DOI: 10.12731/2658-6649-2019-11-5-48-53

УДК 571.27

\title{
ЗАВИСИМОСТЬ МЕТАБОЛИЗМА НЕЙТРОФИЛЬНЫХ ГРАНУЛОЦИТОВ ОТ СТЕПЕНИ ТЯЖЕСТИ РАСПРОСТРАНЕННОГО ГНОЙНОГО ПЕРИТОНИТА
}

\author{
Гвоздев И.И., Беленюк В.Д.
}

Проведено исследование активности НАД(Ф)-зависимых дегидрогеназ нейтрофильных гранулоцитов крови больных с распространённым гнойным перитонитом (РГП) средней и тяжелой степени тяжести. В нейтрофилах больных РГП наблюдается независимое от степени тяжести снижение интенсивности реакций гликолиза и пентозо-фосфатного пути. При этом активность ферментов иикла трикарбоновых кислот повышается только при тяжелой степени тяжести РГП.

Ключевые слова: перитонит; воспаление; нейтрофильные гранулоичтығ; метаболизм.

\section{THE DEPENDENCE OF METABOLISM OF NEUTROPHILIC GRANULOCYTES ON THE DEGREE OF THE ADVANCED PURULENT PERITONITIS}

\section{Gvozdev I.I., Belenyuk V.D.}

A study was conducted on the activity of $N A D(P)$-dependent neutrophilic granulocyte dehydrogenases in patients with widespread purulent peritonitis (WPP) of moderate to severe severity. In the neutrophils of patients with WPP, a decrease in the intensity of glycolysis reactions of the pentose-phosphate pathway is observed independent of the severity. At the same time, the activity of the enzymes of the tricarboxylic acid cycle increases only with severe severity of WPP.

Keywords: peritonitis; inflammation; neutrophilic granulocytes; metabolism.

\section{Введение}

Воспаление является типовым патологическим процессом, развивающимся при большинстве заболеваний, которым организм отвечает на 
самые различные воздействия. Являясь ключевыми клетками воспаления, нейтрофильные гранулоциты, представляют собой высокореактивное звено в иммунной системе. В силу того, что нейтрофилы первыми мобилизуются в очаг воспаления, от их фагоцитарной активности зависит эффективность противомикробной защиты организма [1]. Нейтрофилы способны воспринимать сигналы о дестабилизации внутренней среды и модулировать свои функции, нацеленные на её восстановление. При этом активированные нейтрофилы сами являются эффекторами пусковых и регуляторных механизмов каскадных реакций, обеспечивающих развитие воспаления [2]. В связи с тем, что в основе функциональной активности клеток иммунной системы лежат их метаболические реакции, исследование метаболических параметров клеток иммунной системы позволит улучшить диагностику иммунных нарушений, оценить прогноз течения заболевания и правильно выбрать тактику терапии [3]. Следовательно, изучение метаболизма нейтрофильных гранулоцитов позволит на молекулярном уровне охарактеризовать особенности генеза воспалительных процессов, например, при распространённом гнойном перитоните (РГП). Несмотря на совершенствование методов хирургического лечения и использование мощного арсенала средств интенсивной терапии, летальность от РГП сохраняется на уровне $32-43,9 \%$, а в случае генерализации инфекции и развития полиорганной недостаточности достигает $75,8-100 \%$ [2]. Течение перитонита, характер и особенности развития гнойных инфекционных осложнений определяются не только тяжестью основного патологического процесса, адекватностью выполненного оперативного вмешательства и полнотой послеоперацонного проводимого лечения. Во многом они зависят от происходящих изменений в системе иммунитета [1].

Целью исследования явилась оценка метаболизма нейтрофильных гранулоцитов при РГП средней и тяжелой степени тяжести.

\section{Материалы и методы исследования}

На базе отделения гнойной хирургии Краевой клинической больницы г. Красноярска обследовано 33 больных с РГП средней степени тяжести и 17 больных с РГП тяжелой степени тяжести в возрасте 40-55 лет. Исходную степень тяжести больных определяли по шкале SAPSII. Тяжесть РГП исходно определяли по Мангеймскому индексу перитонита (МИП) и индексу брюшной полости (ИБП). Наличие и степень выраженности ПОН исходно и в динамике определяли по шкале SOFA. При оценке 
тяжести синдрома системной воспалительной реакции (ССВР) мы придерживались критериев ACCP/SCCM. В качестве контроля обследовано 67 здоровых людей аналогичного возрастного диапазона. Исследования проводились в строгом соответствии с этическими нормами Хельсинкской декларации (WMA, 1964). Нейтрофильные гранулоциты выделяли из цельной гепаринизированной крови центрифугированием в двойном градиенте плотности фиколл-урографина: $\rho=1,077$ г/см ${ }^{3}-$ для отделения

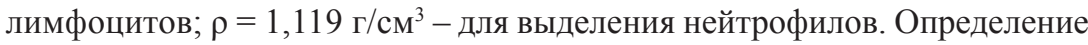
активности НАД(Ф)-зависимых дегидрогеназ в нейтрофилах проводили биолюминесцентным методом. Данным методом определялась активность глюкозо-6-фосфатдегидрогеназы(ГбФДГ), глицерол-3-фосфатдегидрогеназы (ГЗФДГ), лактатдегидрогеназы (ЛДГ), малатдегидрогеназы (МДГ), НАДФ-зависимой малатдегидрогеназы (НАДФМДГ), НАДФ-зависимой глутаматдегидрогеназы (НАДФГДГ), НАД-зависимой глутаматдегидрогеназы (НАДГДГ), НАД-зависимой изоцитратдегидрогеназы (НАДИЦДГ), НАДФ-зависимой изоцитратдегидрогеназы (НАДФИЦДГ), ГР. Биолюминесцентное определение активности НАД(Ф)-зависимых дегидрогеназ проводили по ранее разработанным методикам [3].Статистический анализ осуществляли в пакете прикладных программ Statistica 8.0 (StatSoftInc., 2007). Описание выборки производили с помощью подсчёта медианы и интерквартального размаха в виде 25 и 75 процентилей. Достоверность различий между показателями независимых выборок оценивали по непараметрическому критерию Манна-Уитни.

\section{Результаты исследования}

При исследовании активности НАД- и НАДФ-зависимых дегидрогеназ нейтрофильных гранулоцитов у больных РГП в зависимости от тяжести заболевания обнаружено, что только при тяжелой степени тяжести РГП повышается активность МДГ ( $=0,001)$ и НАДИЦДГ $(\mathrm{p}=0,035)$. При этом активность ГбФДГ, ЛДГ и НАДФГДГ в нейтрофильных гранулоцитах у больных РГП снижается независимо от степени тяжести заболевания $(\mathrm{p}=0,013 ; \mathrm{p}=0,016 ; \mathrm{p}=0,003)$. Также независимо от тяжести заболевания при РГП в нейтрофилах повышается активность НАДФИЦДГ ( $\mathrm{p}=0,033$ ). Исследование активности НАДН-зависимых реакций исследуемых дегидрогеназ при РГП позволило установить, что только при средней степени тяжести заболевания в нейтрофильных гранулоцитах повышается активность НАДН-ЛДГ ( $=0,017)$, НАДН-МДГ ( $=0,015)$ и НАДН-ГДГ ( $=0,014)$. При этом у больных с тяжелой степенью тяжести РГП в нейтрофильных 
гранулоцитах активность НАДН-МДГ снижена относительно уровня, выявленного при средней степени тяжести РГП $(\mathrm{p}=0,035)$.

\section{Обсуждение}

Исследуемые ферменты занимают ключевые позиции на разных метаболических путях, в целом обеспечивающих ее физиологические и функциональные потребности клетки [3]. Так, повышенная активность МДГ и НАДИЦДГ в нейтрофилах при тяжелой степени тяжести РГП определяют высокую интенсивность субстратного потока по циклу трикарбоновых кислот [4]. Причем для поддержания высокой интенсивности субстратного потока по циклу Кребса в клетках повышается активность вспомогательной дегидрогеназной реакции - НАДФИЦДГ (независимо от степени тяжести заболевания).

Необходимо отметить, что функциональная активность нейтрофильных гранулоцитов во многом определяется не уровнем аэробного дыхания, а интенсивностью анаэробного. Следовательно, исходя из повышения активности НАДН-зависимых реакций ЛДГ и МДГ в нейтрофильных гранулоцитах именно у больных РГП со средней степенью тяжести заболевания, можно предположить увеличение активности терминальных реакций гликолиза и, соответственно, высокий уровень наработки НАДН в цитоплазматическом компартменте клеток. В то же время, независимо от степени тяжести заболевания в нейтрофильных гранулоцитах снижена активность ключевой и инициализирующей реакции пентозофосфатного цикла (ГбФДГ), аэробной реакции ЛДГ и НАДФГДГ. Подобное состояние внутриклеточных метаболических процессов при РГП отражает ингибирование пластических реакций и окисления лактата на фоне активации энергетических процессов.

\section{Заключение}

Таким образом, у больных РГП на фоне снижения активности ферментативных реакций, характеризующих состояния пластических процессов и окисление лактата, повышается активность энергетических процессов: терминальных реакций гликолиза - при средней степени тяжести РГП; НАД-зависимых дегидрогеназных реакций, определяющих интенсивность аэробного дыхания, - при тяжелой степени тяжести РГП. В связи с тем, что функциональная активация нейтрофильных гранулоцитов в большей степени определяется анаэробными процессами, изменения метаболических реакций в нейтрофильных гранулоцитах при средней степени тя- 
жести РГП определяют более высокую реактивность фагоцитирующих клеток, чем при тяжелой степени РГП.

\section{Список литературы}

1. Савченко А.А. Черданцев Д.В., Первова О.В., Борисов А.Г., Гвоздев И.И., Шапкина В.А. Клиническое состояние и хемилюминесцентная активность нейтрофильных гранулоцитов больных распространённым гнойным перитонитом в динамике послеоперацитонного периода// Бюллетень сибирской медицины. 2014. Т. 13. № 6. С. 10-19.

2. Гвоздев И.И., Беленюк В.Д., Курбанов Д.Ш., Шапкина В.А., Мошев А.В., Кощеев В.Н. Оценка хемилюминесцентной активности нейтрофильных гранулоцитов при распространенном гнойном перитоните// Вестник Хакасского государственного университета им. Н. Ф. Катанова. 2014. № 8. C. $31-33$.

3. Куртасова Л.М., Савченко А.А., Шмидт А.Р. Структурно-метаболические особенности иммунокомпетентных клеток у детей раннего возраста с атопической бронхиальной астмой // Аллергология. 2003. №4. С. 17-21.

4. Прохоренков В.И., Куртасова Л.М., Савченко А.А., Чесноков А.Б., Шмидт А.Р. Некоторые особенности иммунного статуса и метаболического состояния иммунокомпетентных клеток у детей с атопическим дерматитом // Вестник дерматологии и венерологии. 2000. № 3. С. 20-22.

\section{References}

1. Savchenko, A.A. Cherdantsev D.V., Pervova O.V., Borisov A.G., Gvozdev I.I., Shapkina V.A. Klinicheskoe-sostoyanie i hemilyuminescentnaya aktivnost nejtrofilnyh granulocitov bolnyh rasprostranyonnym gnojnym peritonitom v dinamike posleoperacitonnogo perioda [Clinical status and chemiluminescent activity of neutrophilic granulocytes in patients with advanced purulent peritonitis in the dynamics of the postoperative period]. Byulleten sibirskoj mediciny. 2014. V.13. №6, pp. 10-19.

2. Gvozdev I.I., Belenyuk V.D., Kurbanov D.Sh., Shapkina V.A., Moshev A.V., Koscheev V.N. Ocenka hemilyuminescentnoj aktivnosti nejtrofilnyh granulocitov pri rasprostranennom gnojnom peritonite [Evaluation of the chemiluminescent activity of neutrophilic granulocytes with widespread purulent peritonitis]. Herald of the Khakass State University. 2014. No. 8. P. 31.

3. Kurtasova L.M., Savchenko A.A., Shmidt A.R. Strukturno-metabolicheskiye osobennosti immunokompetentnykh kletok $u$ detey rannego vozrasta s atopicheskoy bronkhial'noy astmoy [Structural and metabolic features of immunocom- 
petent cells in young children with atopic asthma]. Allergologiya, 2003. № 4, pp. 17-21.

4. Prokhorenkov V.I., Kurtasova L.M., Savchenko A.A., Chesnokov A.B., Shmidt A.R. Nekotoryye osobennosti immunnogo statusa i metabolicheskogo sostoyaniya immunokompetentnykh kletok $\mathrm{u}$ detey s atopicheskim dermatitom [Some features of the immune status and metabolic state of immunocompetent cells in children with atopic dermatitis]. Vestnik dermatologii $i$ venerologii. 2000. № 3 , pp. 20-22.

\section{ДАННЫЕ ОБ АВТОРАХ}

Гвоздев Иван Игоревич, младший научный сотрудник лаборатории клеточно-молекулярной физиологии и патологии ФГБНУ «НИИ медиџинских проблем Севера» ул. Партизана Железняка, 3 г, г. Красноярск, 660022, Российская Федераиия Leshman-mult@mail.ru

Беленюк Василий Дмитриевич, младший научный сотрудник лаборатории клеточно-молекулярной физиологии и патологии ФГБНУ «НИИ медицинских проблем Севера» ул. Партизана Железняка, 3 г, г. Красноярск, 660022, Российская Федераиия

\section{DATA ABOUT THE AUTHORS}

Gvozdev Ivan Igorevich, Junior Research Officer of the Laboratory of Cell Molecular Physiology and Pathology

Research Institute for Medical Problems of the North

3 g, Partizana-zheleznyaka Str., Krasnoyarsk, 660022, Russian Federation

Leshman-mult@mail.ru

Belenyuk Vasily Dmitrievich, Junior Research Officer of the Laboratory of Cell Molecular Physiology and Pathology Research Institute for Medical Problems of the North 3 g, Partizana-zheleznyaka Str., Krasnoyarsk, 660022, Russian Federation 